\title{
CATHELICIDIN - ITS STRUCTURE, FUNCTION AND THE ROLE IN AUTOIMMUNE DISEASES
}

\author{
Magdalena POLCYN-ADAMCZAK, Zofia I. NIEMIR
}

Laboratory for Molecular Nephrology, Department of Nephrology, Transplantology and Internal Medicine, Poznań University of Medical Sciences

\author{
DOI: $10.2478 / \mathrm{acb}-2014-0005$
}

Summary: Antimicrobial peptides are widely distributed in nature, and they are found in both Prokaryotes and Eukaryotes. Due to their characteristics, structure, functions and mode of action, they are divided into several groups. The only member of this family occurring in humans is cathelicidin - LL-37. It is produced as an inactive hCAP18 propeptide. The propeptide's C-terminal fragment becomes a mature peptide subsequently to its enzymatic cleavage. LL-37 contains 37-amino acid residues, folds into $\alpha$-helical structure and has amphipathic properties. Cathelicidin mechanism of action consists in the binding of LL-37 to the bacterial phospholipid membrane until a threshold concentration is reached, followed by the cytoplasm disintegration and leakage, and, finally, cell death. The peptide is expressed in several cells, for instance in the epithelial cells of testis, keratinocytes in the skin, leukocytes, monocytes, neutrophils, as well as T, B, and NK cells. Cathelicidin is a multifunctional molecule. It can serve as a mediator in inflammatory processes and/or as a natural antibiotic against Gram-negative and Gram-positive bacteria, viruses, and fungi. It is chemotactic for mononuclear cells, neutrophils, eosinophils, mast cells and $\mathrm{T}$ lymphocytes. LL-37 induces expression of chemokines, neutralises endotoxins, stimulates angiogenesis and apoptosis, as well as it boosts wound healing. Recent data have revealed an important role of LL-37 in the pathogenesis of systemic lupus erythematosus due to an impaired degradation of components in the neutrophil extracellular traps.

Key words: cathelicidin, structure, function, NETosis, systemic lupus erythematosus

\section{INTRODUCTION}

The surrounding us environment is rich in bacteria, including pathogens. Therefore all living bodies evolutionarily developed a kind of an immunological system. In primitive Eukaryotes this system consists of a physiological barrier and/ 
or molecules able to kill or inhibit development of infectious agents [51]. Antimicrobial peptides (AMPs) belong to direct defence effector molecules in the human and animals' immunological systems. AMPs are frequent in nature, being produced by mammals, birds, amphibians, reptiles, insects, plants and microbes [3]. The fact that these peptides did survive in the course of evolution reflects their vital role in the immune system [51]. Irrespective of their place of occurrence, scope of action or structure, antimicrobial peptides are composed of 60 amino-acid residues (usually L-amino-acids). They are positively charged, hydrophobic and/or amphipathic. They act within the cell membranes $[32,50]$. These peptides were first described in the early 1980s, in wounded frogs and toads [32]. The excretion of a substance subsequently named marginin was observed directly following an injury. The substance was binding to a microbial cell membrane, destroying it and in this way killing the microbe. AMPs usually involve small cationic polypeptides, able to kill or inhibit development of pathogens. They can also activate the cellular and immune mechanisms. They constitute a protection shield in the epithelium, where their expression may be induced during an infection or inflammation. AMPs' primary functions include: elimination of infectious pathogens [31, 44, 48], stimulation of cytokines' secretion [16, 40, 48] and of angiogenesis [7], inhibition of apoptosis [8, 23, 30], and activation of chemotactic [34, 50, 55], dendritic [12, 15, 32] and mast [7] cells. Meanwhile, these peptides participate in maturation and activation of autophagy [22], as well as in the process of wound healing [51]. Their insufficiency may lead to diseases, such as atopic dermatitis [2,10], Kostmann disease [32], cystic fibrosis [50] or autoimmune diseases, including systemic lupus erythematosus (SLE) [26]. Understanding the AMPs' mechanism of action may facilitate the development of antimicrobial drugs imitating human immune system. The peptides are synthesised fast and are present shortly after an infection in order to immediately neutralise the pathogens [29]. Bacteria undergo a division every 20 minutes. Therefore, a host body needs to be equipped with the defence mechanisms that exert an effect prior to a targeted immune response. The latter one may be triggered too late to compete with the kinetics of the pathogens' proliferation $[32,50]$. The AMPs mechanism of action consists in the peptide binding with the bacterial phospholipid membrane until a threshold concentration is reached, followed by the leakage, depolarisation and disintegration of the cell membrane, and, consequently, cell death [1, 14, 46].

AMPs were divided into three groups, which reflects their structure, characteristics, as well as their scope and mode of action $[2,9,48]$ :

- $\quad$ cysteine-free linear $\alpha$-helical peptides of amphipathic properties, e.g. marginins, cecropins and cathelicidins,

- $\quad$ peptides with three disulphide bonds, and a $\beta$-sheet structure, such as defensins and protegrins,

- $\quad$ peptides rich in one or several amino-acids, such as proline, arginine, tryptophan or histidine. 
Subsequently, two additional groups were distinguished: peptides with one disulphide bond and peptides functioning as parts of larger proteins [32, 40, 47]. More than 1500 different AMPs have been described so far. The only $\alpha$-helical peptide occurring in humans is cathelicidin LL-37. It plays a vital role in the first line defence against infections and systemic invasions by pathogens in the place of an inflammation or wound $[32,34]$.

\section{CATHELICIDIN'S MOLECULAR STRUCTURE}

The cathelicidin molecule was discovered in 1995 [37, 40, 50]. Once isolated from the neutrophils, the bovine Bac5 peptide was observed to come from inactive precursors. Cloning of the precursor-coding cDNA proved that the proteins bind to each other forming a mature peptide [37]. Cathelicidin was first described in leukocytes and the cell nucleus, and subsequently it was discovered in other cells and tissues: granulocytes, keratinocytes, monocytes $[48,50]$, as well as in skin, intestine and pulmonary epithelium $[32,51]$. Cathelicidin contains a highly conserved N-terminal domain, composed of around 100 amino-acid residues. The $14 \mathrm{kDa}$ cathelin domain contains an $\mathrm{N}$-terminal signal peptide consisting of around 30 amino-acid residues, while the $\mathrm{C}$-terminal fragment codes the cationic antimicrobial peptide $[32,40]$. Genes responsible for the cathelicidins' synthesis contain four exons of 1963 base pairs (bp). The highly conservative exons: 1, 2 and 3, code the signal sequence and cathelin domain, while the variable exon 4 is responsible for coding the mature peptide $[10,47]$. Cathelicidin is stored in neutrophilic granules. It has a positively charged molecule ( $+6, \mathrm{pH}$ of about 7.4$)$, and contains basic and hydrophobic amino acids. The LL-37 structure folds into the amphipathic alpha-helix containing 37 amino-acids, including two leucines. The molecule is cysteine-free (Fig. 1) [32, 40, 44, 48]. At first, 39 amino acid residues were observed in the Cterminal cathelicidin fragment, and named FALL-39 (Phe-Ala-Leu-Leu) [40, 47]. However, following the peptide's isolation from the neutrophils, subsequent studies showed that it was shorter by two amino-acids and had two leucines at the beginning [47]. Numerous authors focused on identifying the primary peptide region, able to trigger an antimicrobial response. There were also frequent attempts to define the peptide's shortest fragment that would be capable of performing an antimicrobial activity. Studies on LL-37 have shown that the N-terminal helix participates in chemotaxis, protein oligomerization, proteolytic resistance and haemolytic activity. The C-terminal helix is responsible for the antimicrobial, antiviral and anticancer effects, while the C-terminal tail takes part in formation of the cathelicidin tetramers. The LL-37 sequence, referred to as FK-13 (17-19 amino-acids) and KR-12 (18-29 amino-acids) forms the peptide core, capable of performing an antimicrobial activity. It overlays the C-terminal helix [51]. 
Cathelicidin is detected as the $18 \mathrm{kDa}$ propeptide: hCAP-18, showing no antimicrobial properties. It contains: a signal peptide composed of 30 amino-acids, 99-144 amino-acid cathelin domain and AMPs composed of 12-100 amino-acids $[37,40,50]$. The hCAP-18 propeptide is synthesised in the bone marrow and stored in mature neutrophils, lymphocytes' subpopulation and monocytes. The peptide has two disulphide bonds between the cystine C85-C96 and C107-C124 residues. Once protease 3 releases the C-terminal cation fragment from the hCAP-18 propeptide, the propeptide turns into LL-37 $[32,34]$. Next, there was a process alternative to observed action of protease 3, namely: the process of detaching hCAP-18 from ALL-38 which is an inactive hCAP-18 precursor, by prostate gastrixin protease in a suitable $\mathrm{pH}$ [11]. LL-37 detected in sweat may undergo degradation into KR-20, RK-31 and KS-30, which is dependent on serine protease. The three fragments were observed to manifest an increased antimicrobial activity [10]. The C-terminal fragments, shorter by 5 amino-acids, were synthesised too, which also led to an increase in antimicrobial activity [10]. On the skin surface, LL-37 may be transformed by the serine or microbial protease, e.g. the Staphylococcus aureus aureolysin, into small fragments. These fragments do keep their antimicrobial capabilities, meanwhile loosing their immunomodelling and stimulating properties [10, 51].

It is suggested that the hCAP18-to-lipoproteins plasma binding through the antimicrobial domain may act as a protection against the potentially cytotoxic effect of mature LL-37 [11]. Moreover, the cathelin domain can protect the peptide from the proteolytic degradation [48]. The LL-37 central part (11-32 residues) takes the form of an amphipathic $\alpha$-helix, characteristic of membrane-penetrating proteins. This suggests that the region plays a vital role in toxic activity of the peptide [32, 51]. It can occur as a monomer, dimer or a tetramer in water solutions, at a very low concentration [48]. The LL-37 ability to form oligomers due to its positive charge is impressive. According to the authors, this ability stems from the fact that the N-terminal LL-37 fragment contains 30\% of hydrophobic amino-acids and, consequently, may act as the oligomer hydrophobic core. Carrying 5 negatively charged termini, located along the peptide chain, it can form saline bonds with positively charged termini and, by this, it stabilises the oligomer. It is this ability to form oligomers in water solutions that protects LL-37 against proteolytic digestion [48].

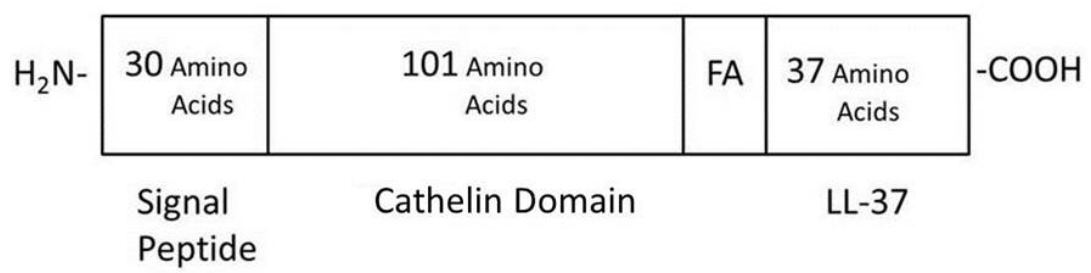

FIGURE 1. Schematic diagram of the human hCAP-18 molecule (modification based on Witkowska D. et al. [50] 


\section{AMPS MECHANISM OF ACTION}

AMPs constitute a highly diverse group, synthesised by the cells and tissues of the invertebrates, animals and plants. The amphipathic structure, cationic charge and their size enable AMPs to bind and build into cell membranes by means of different mechanisms: the so-called "barrel-stave", "carpet" and "toroidal" ones $[1,7,14,20]$.

The barrel-stave mechanism makes the proteins accumulate on a pathogen's surface, forming a shape that resembles the staves of a barrel. Consequently, the inter-membrane channels are formed, where the peptide's hydrophobic surface interacts with the lipid core on the membrane's surface, while the internal, hydrophilic one forms water slits [20]. This mechanisms was suggested to have 4 basic stages:

- $\quad$ protein monomer binding to the membrane,

- $\quad$ identification of membrane-bound monomer molecules, which results in formation of a peptide group on the surface,

- incorporation of at least two monomers into the membrane and formation of the slits,

- gradual incorporation of other monomers and an increase in the number of slits.

The penetration of membrane by amphipathic $\alpha$-helises, in the form of monomers, is an energy-consuming process. For this reason, the barrel-stave mechanism is not carried out until a group of monomers is formed on the membrane surface. In the final process, the fatty acyl regions of the lipid membrane cannot be directly bound with the polar surface of a single $\alpha$-helix amphipathic surface, due to the low charge of the hydrogen bonds [14].

Subsequently to the "barrel-stave" mechanism, another one was described, namely the so-called, "carpet" mechanism. It was first defined for the S dermaseptin [2] and cecropin [20], as well as LL-37 [8, 29, 32]. The mechanism makes the peptides bind with the phospholipid pathogen membrane surface, covering it entirely. In the first phase, the negatively charged bacterial membrane interacts with the positively charged peptide molecule. Once the threshold concentration is reached, the peptides protrude through the bacterial cell membrane (Fig. 2). The peptides are attached to phospholipids during the entire leakage process. Contrary to the "barrel-stave" mechanism, in the "carpet" model positively charged peptides along the peptide chain are not incorporated into the hydrophobic core, nor attached to the hydrophilic surface.

The "carpet" model requires 3 conditions to be met [29]:

- $\quad$ protein monomer binding to the phospholipid head,

- $\quad$ peptide monomers have to be arranged on the membrane surface in such a way that the positively charged amino-acids' hydrophilic surface covers the negatively charged phospholipid surface or a water molecule,

- molecule's rotation results in directing the hydrophobic residues towards the hydrophobic membrane core. 
A)

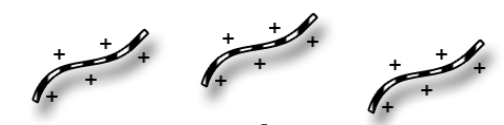

B)

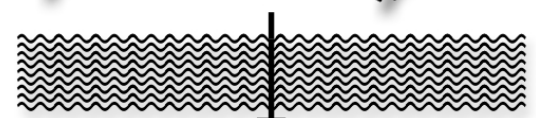

C)

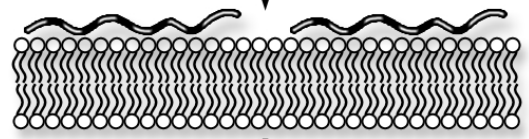

E)
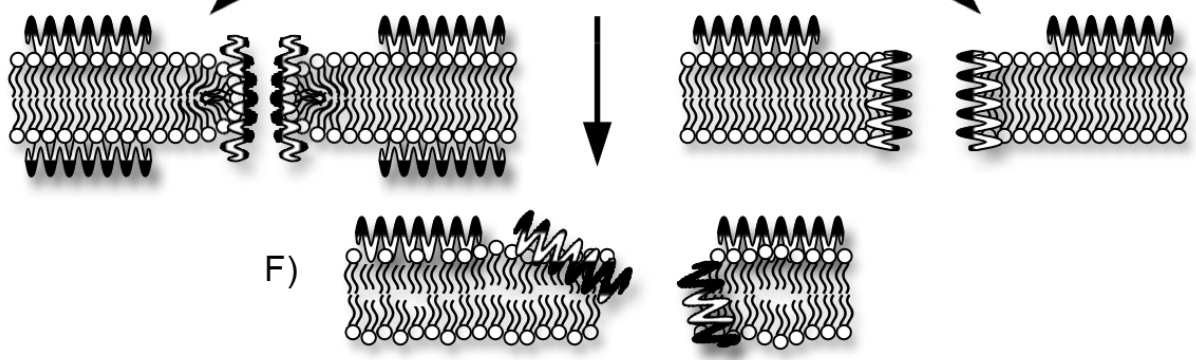

H)

FIGURE 2. Modes of action of AMPs (modification based on Bahar A. A. et al. [2]

A - electrostatic attraction to anionic microbial surface;

$\mathrm{B}$ - passage across the outer membrane and/or peptidoglycan layer;

$\mathrm{C}$ - electrostatic attraction to anionic phospholipids in the cytoplasmic membrane;

$\mathrm{D}$ - structuring, membrane insertion and accumulation;

$\mathrm{E}$ - toroidal pore formation;

$\mathrm{F}$ - carpet mechanism for membrane permeabilization;

$\mathrm{G}$ - barrel stave pore formation;

$\mathrm{H}$ - secondary effects (DNA/protein binding, membrane compositional rearrangements, interference with essential cellular machinery).

Irrespective of the mechanism which is followed by the peptides attacking the bacterial cell membrane, the membrane is damaged, disintegrated and depolarised, which results in irreversible changes, structure decomposition, cytoplasm leakage and, consequently, death of the pathogen. 
During a "toroidal" process, peptide aggregation on the membrane surface results in narrowing of the membrane walls and formation of the so-called toroidal pores [2] which enable low-molecular-mass proteins to protrude to the internal membrane prior to the complete membrane lysis. This process is referred to as the self-promoting uptake. The toroidal mechanism makes the lipids lean back on one another and inwards [14], contrary to the "barrel-stave" mechanism.

\section{LL-37 CATHELICIDIN FUNCTION}

LL-37 and its precursor are found in different concentrations in a number of tissues and cells. Due to their amphipathic structure, they both show direct affinity for bacterial cell membranes, as well as they participate in the effector mechanisms of the acquired immunity through the recruitment and stimulation of various cells. This correlates with the peptide's double nature: of a peptide antibiotic and of a signal cell $[37,48,50]$. Cathelicidin is detected e.g. in the skin, squamous epithelium of air passages, mouth, tongue, oesophagus, duodenum, cervix and vagina $[1,40$, 51], epididymis and testis [7, 47], as well as in the fluid which lines the inside of the air passages $[7,32,51]$. The peptide is also produced in large concentrations in the place of an infection or skin damage [40]. Moreover, studies have shown its chemotactic abilities to attract rat peritoneal mast cells (in the optimal concentration equal to $5 \mu \mathrm{g} / \mathrm{mL}$ ). Cathedicilin also induces histamine and the intracellular $\mathrm{Ca}++$ release, which indicates that the mast cells are attracted towards the place of inflammation [32]. High hCAP18 mRNA expression occurs together with IL-6, one of interleukins, which accounts for the role of the cytokine in the hCAP18 gene expression. LL37 is chemotactic for neutrophils, monocytes [37, 44, 48, 50], and T cells. It shows the greatest affinity for the CD4 cells, selectively caught by the peptide, which may indicate that the cells producing LL-37 in tissues regulate the assembly of particular subgroups of lymphocytes [37]. An increased LL-37-coding gene expression was shown in lymphocytes, various cell lines and clones of NK, $\gamma \delta$, T, and B cells, as well as monocytes. An increased secretion of the peptide was accompanied by the negative IL-6- and IFN $\gamma$-stimulated transcription of LL-37-coding gene [37, 48]. Cathelicidin induces immunomodulation by the N-N-formylpeptide-like1 receptor (FPRL-1) and the receptor G-protein, as well as the nucleotide (P2X7) and signal (TLR) receptor [40, 44]. It also mediates chemotaxis which can be impeded by an antagonist or by the pertussis toxins. Furthermore, the peptide participates in the FPRL-1-mediated angiogenesis, where G-protein represents the receptor protein on the endothelial cells. Due to the interaction with FPRL-1, cathelicidin participates in mechanisms of the innate and acquired immunity, as it attracts neutrophils, monocytes and $\mathrm{T}$ cells to the site of inflammation. It can inhibit or stimulate apoptosis, 
depending on the type of cells. LL-37 inhibits the activity of caspase 3 and promotes apoptosis in the blood vessel smooth muscle cells, neutrophils and T cells, while it exerts an inhibitory effect on apoptosis in keratinocytes and fibroblasts [23]. Cathelicidin cytotoxic and antimicrobial properties which lead to the membrane damage are abolished by the addition of serum [48], or use of standard bacterial media [31, 48]. They are similarly affected by an environment rich in salt, as described in patients with cystic fibrosis [32]. When the sodium chloride concentration increases, LL-37 activity decreases four to five times. This is related to the inactivation of other agents in the air passage epithelium or an impairment of the cystic fibrosis transmembrane conductance regulator (CFTR). LL-37 induces degranulation of mast cells which appear first in the site of an inflammation or an injury, phagocytose and kill bacteria [31,37]. The mast cell degranulation leads to an inflammation and release of histamine mediators [32], to chemotaxis of neutrophils, which may increase blood vessel permeability and attract monocytes to the site of inflammation [43]. LL-37 manifests a broad spectrum of immunomodulatory activity: it acts synergistically with other AMPS, stimulates cell proliferation by binding with FPRL-1 and acts as a chemoattractant for neutrophils, monocytes and T CD4+ cells [7, 31]. Cathelicidin, LL-37, is bactericidal in a number of ways, and acts against the Gram negative (Pseudomonas aeruginosa, Escherichia coli) bacteria and Gram positive (Staphylococcus aureus, Staphylococcus epidermidis) bacteria, viruses (HIV, influenza) and fungi (Candida albicans). Certain species are LL-37-resistant [15, 40, 51], while other are susceptible to its activity [48], which accounts for the high selectivity of the peptide towards Procaryotes. The peptide is bactericidal towards the Streptococcus bacteria, an important pathogen for newborns [48, 51]. According to the authors, this activity serves as a protection shield while the newborns' immunological response is being developed. Cathelicidin was detected in a newborn amniotic fluid and skin, where it constitutes an innate antimicrobial barrier and, therefore, acts as a protecting agent. Mice deprived of their LL-37 analogue gene (CRAMP; cathelicidin-related antimicrobial peptide) are more prone to be infected by the group A streptococcus than wild mice $[32,50,51]$. Studies both on mice and humans have proved that cathelicidin expression is increased in response to an injury or group A streptococcus infection [48, 51]. The presence of LL-37-specific antibodies correlated with the lack of the peptide expression and a negative response to treatment of chronic ulceration [38]. LL-37 impedes the Pseudomonas aeruginosa bacteria growth. It also prevents the development of the bacterial biofilm, e.g. by decreasing the bacterial adhesion to the surface. Transferring the LL-37/hCAP gene into the air passages of mice infected by the pathogen results in a significant decrease in the number of bacteria [31]. Studies on LL-37 and CRAMP showed their weak (MIC $>64 \mu \mathrm{M}$ ) antimicrobial activity against Staphylococcus aureus, a stronger one (MIC $4-16 \mu \mathrm{M}$ ) towards Pseudomonas aeruginosa, and the strongest 
(MIC $5-16 \mu \mathrm{M}$ ) against Escherichia coli and other species which seldom attack skin $[15,32,40,48,51]$. LL-37 and the propeptide undergo the in vitro and ex vivo degradation during a leakage from a wound containing the Pseudomonas aerugino$s a$ bacteria, which produce elastase $[40,50]$.

Cathelicidins neutralise lipopolysaccharide (LPS), an endotoxin present in the Gram-negative cell membranes, which causes septic shock by induction of proinflammatory cytokines. LL-37 was shown to bind with LPS, inducing the MCP-1, IL-6 [23] and IL-8 [45] expression. It also neutralises the endotoxin's activity by blocking the LPS-to-CD14+ binding and inhibiting the cytokine production. The peptide's ability to inhibit the cytokine production depends on the strength of its binding with LPS [7]. LL-37 inhibits the IL-6, IL-8, IL-10 [21] and IL-1 $\beta$, IL-8 gene expression, as well as the expression of the intercellular adhesion molecule (ICAM-1) induced by bacterial LPS. Park et al. proved that LL-37 inhibits the collagen expression in fibroblasts, by inducing the ERK (extracellular signal-regulated kinase) phosphorylation [39]. LL-37 is also known to act pro-apoptotically [8, 23, 30, 55]. Meanwhile, the expression of cyclooxygenase-2 (COX-2) and prostaglandin-2 (PGE-2), responsible for the anti-apoptotic protection, was proved to increase in the LL-37-stimulated keratinocytes. Moreover, LL-37 induced expression of the apoptosis-2 (IAP-2) inhibitor, implicated in the COX-2/PGE-2 anti-apoptotic pathway [8].

LL-37 activity is much more frequently $[32,40]$ boosted in cases of, e.g., psoriatic skin changes [10, 42], SLE [18, 25], contact dermatitis [28, 34], bacterial infections [44, 48, 51], synovitis [19], chronic rhinitis [7], tracheal aspirates of newborn infants $[7,32]$, cystic fibrosis [31], sarcoidosis [44, 50] or cancer [7, 48]. A decrease in the peptide activity was observed, e.g., in the atopic dermatitis [42], chronic epithelial ulceration [48, 50], duodenum infections [7] and acute myeloid leukaemia [41]. The lack of LL-37 expression was noticed in granulocytes and the saliva of patients with Kostmann disease $[32,50]$.

\section{NET, NETOSIS AND ITS ROLE IN THE AUTOIMMUNE DISEASES}

Studies conducted in the last decade showed that activated neutrophils release a complex rich in nucleic DNA, histones, LL-37 and cytoplasmic inclusions to the extracellular space. This involves formation of a structure called the neutrophil extracellular trap (NET) for extracellular pathogens. Once trapped, the pathogens are destroyed. Neutrophils die subsequently to the NET release (NETosis) [13, 26, $53,54,55]$. In neutrophils activated by, e.g., LPS, phorbol myristate acetate (PMA), or IL-8, the nucleic envelope is dissolved, while chromatin is decompressed and fused with its granule proteins. When a cell membrane is damaged, the complex is released to the extracellular space. NET is also released by neutrophils stimulated 
by immune complexes; their chromatin is decondensed by means of enzymes: neutrophil elastase and myeloperoxidase [52]. Elastase degrades the histone 1 bond and the nucleus, which leads to the chromatin decondensation, additionally boosted by myeloperoxidase [33]. Moreover, while NET is formed, histones 3 undergo citrullination (deimination), which transforms positively charged, side arginine chains into polar, uncharged citrullin residues [27, 49]. This process is catalysed by the peptidylarginine deiminase 4 (AMPS4) located in the neutrophile cell nucleus. The nuclear envelope is disrupted, allowing chromatin to bind antimicrobial agents and to release NET [6, 53]. According to Neeli et al. [35], the MAC-1 integrin also takes part in initiation of the changes in the neutrophil cytoskeleton, enabling nucleus and cell membrane disintegration and releasing the trap.

Meanwhile, NET acts as an agent protecting against pathogens, such as bacteria, viruses, protozoans and fungi. Therefore, it concurrently exposes immunostimulatory molecules, activates plasmacytoid dendritic cells (pDC) to produce INF- $\alpha$, acts toxically on epithelium, participates in the antibody production and complement activation, as well as has its role in the organ damage [4, 5, 13, 24, 26, 52]. Furthermore, citrullinated histones impair endothelial cells [17] and contribute to the development of new autoantigens [9] activated by NET protein exposure, due to the DNase inhibitors protecting the DNA against degradation [26]. This DNA degradation inhibition results from the LL-37 protective function and the high level of antibodies against the NET components, or its binding with $\mathrm{Clq}$ [53]. According to Lande et al. the correlation between the level of LL-37 antibodies and dsDNA indicated that the neutrophil-derived LL-37 works as the B cell auto-antigen when linked to DNA. On the other hand, Kahlenberg et al. pointed out that there is a simultaneous activation of caspase-1, the main inflammatory enzyme, and that this activation proves that the DNA-LL-37 complex is not indispensable [24]. According to Kahlenberg et al., caspase-1 can be activated due to the potassium loss, induced by means of the ATP-activated P2X7R receptor. As stated by Garcia-Romo et al., NETosis is also triggered by the FcyRIIabinding complexes containing ribonucleoprotein (RNP) [13]. RNP- containing complexes stimulate the neutrophils to produce reactive oxygen forms, which triggers activation of neutrophil enzymes and results in their dislocation to the cell nucleus, followed by NET release. Consequently, immunogenicity and the DNA uptake by pDC are increased [32, 51].

In case of certain diseases, e.g. the chronic granulomatous disease, there is no possibility of releasing NET due to the mutations in nicotinamide adenine dinucleotide phosphate (NADPH) oxidase [54]. However, introduction of $\mathrm{H}_{2} \mathrm{O}_{2}$ brings back this possibility, as proved by Nishinak et al. [36]. Diseases such as small vessel vasculitis (SVV) or SLE are characterised by the presence of antibodies against neutrophil cytoplasm (ANCA), targeted at myeloperoxidase (MPO) and proteinase 3 (PR3). ANCA binding with MPO and PR3 results in the activation of neutrophils and NETosis. The ANCA-MPO complex also activates myeloid dentritic cells (mDC). A treatment with 
DNase inhibits NET formation and prevents from vessel inflammation. LL-37 may also form complexes with its own RNA and transform it into a strong $\mathrm{mDC}$ stimulator (with the use of TLR7 and 8 receptors) [12]. The LL-37-RNA complex, released subsequently to cell death, is transported to $\mathrm{pDC}$ and $\mathrm{mDC}$. It induces TLR7 activation in $\mathrm{pDC}$ and triggers IFN- $\alpha$ secretion, while its activities in $\mathrm{mDC}$ consist in induction of TNF- $\alpha$ and IL- 6 , as well in their differentiation into mature dendritic cells. mDC maturation is triggered by stimulation of the endosomal TLR8s and reinforced by making $\mathrm{pDC}$ to produce IFN- $\alpha$. In vivo tests showed that the number of LL-37-RNA complexes correlates with the number of mature $\mathrm{mDC}$ [53], which was confirmed by Sun et al. [45]. Sun et al. proved a positive correlation between the pDC activation, expressed as increased IFN- $\alpha$ secretion, and the LL-37 expression [45]. LL-37, in turn, is capable of activating $\mathrm{pDC}$ to produce $\operatorname{IFN}-\alpha[5,13,26]$.

DNase1, present in serum, is responsible for the NET degradation. SLE patients showed slower NET degradation, caused by low DNase activity, its inhibitors or NET antibodies, preventing DNase to protrude through NET $[5,18]$. Numerous research groups have suggested that the lack of balance between NET formation and its clearance in SLE patients may result in lower immune tolerance and tissue damage [13, $18,24,25,52]$. Low density neutrophils, frequent among the SLE patients, are the ones responsible for NETosis and immunostimulatory protein exposure in this group [53]. Moreover, NET was frequently shown to act as an activator of a combined inflammatory process, at least partially with increased LL-37 release [24, 52]. LL-37 activates the NLRP3 macrophage inflammatory receptor (particularly its M1 subtype), with the use of P2X7R. Furthermore, NET production is boosted by IL-18 release. This indicates that there exists a new mechanism amplifying the inflammatory response through a loop, where IL-1 $\beta$ - and IL-18-induced NETosis boosts the release of extracellular nets by the activated neutrophils [24].

\section{CONCLUSION}

Recent years have shown an increased significance of antimicrobial peptides, including LL-37. These peptides are synthesised fast, at a low metabolic cost, and they are present in large amounts immediately following an infection. The peptides are produced by various cell types: macrophages, neutrophils, keratinocytes, and epithelial cells. They constitute a bond between the innate and acquired immunological response. The LL-37 molecule acts as an antimicrobial peptide, leading to death of pathogens or to inhibition of their growth. The molecule plays an immunostimulatory role in the immunological response. It induces changes in cell membrane dynamics, which are related to activation of membrane receptors. However, apart from its desired activity, the molecule participates in triggering the autoimmune diseases. 


\section{REFERENCES}

[1] Bahar AA, Ren D. Antimicrobial Peptides. Pharmaceuticals (Basel) 2013; 6 (12): 1543-1575.

[2] Ballardini N, Johansson C, Lilja G, Lindh M, Linde Y, Scheynius A, Agerberth B. Enhanced expression of the antimicrobial peptide LL-37 in lesional skin of adults with atopic eqzema. $\mathrm{Br} \mathrm{J}$ Dermatol 2009; 161 (1): 40-7.

[3] Boman HG. Peptide antibiotics and their role in innate immunity. Annu Rev Immunol 1995; 13: 61-92.

[4] Bosch X. Systemic lupus erythematosus and the neutrophil. N Engl J Med 2011; 365 (8): 758-60.

[5] Branzk N, Papayannopoulos V. Molecular mechanisms regulating NETosis in infection and disease. Semin Immunopathol: 2013; 35 (4): 513-530.

[6] Brinkmann V, Zychlinsky A. Neutrophil extracellular traps: is immunity the second function of chromatin? J Cell Biol 2012; 198 (5): 773-83.

[7] [Bucki R, Leszczyńska K, Namiot A, SokoŁowski W. Cathelicidin LL-37: A multitask antimicrobial peptide. Arch Immunol Ther Exp, 2010; 58: 15-25.

[8] Chamorro Ci, Weber G, Grönberg A, Pivarcsi A, StÅhle M. The human antimicrobial peptide Ll-37 suppresses apoptosis in keratinocytes. J Invest Dermatol 2009; 129 (4): 937-44.

[9] DarRah E, AndRade F. NETs: the missing link between cell death and systemic autoimmune diseases? Front Immunol 2013; 3: 428.

[10] Dombrowski Y, Schauber J. Cathelicidin LL-37: a defense molecule with a potential role in psoriasis pathogenesis. Exp Dermatol 2012; 21 (5): 327-30.

[11] Edström AML, Malm J, Frohm B, Martellini JA, Giwercman A, Mörgelin M, Cole AM, Sørensen OE. The major bactericidal activity of human seminal plasma is zinc-dependent and derived from fragmentation of the semenogelins. J Immunol 2008; 181 (5): 3413-3421.

[12] Ganguly D, Chamilos G, Lande R, Gregorio J, Meller S, Facchinetti V, Homey B, Barrat FJ, Zal T, GILLIET M. Self-RNA-antimicrobial peptide complexes activate human dendritic cells through TLR7 and TLR8. J Exp Med 2009; 206 (9): 1983-94.

[13] Garcia-Romo GS, Caielli S, Vega B, Connolly J, Allantaz F, Xu Z, Punaro M, Baisch J, Guiducci C, Coffman RL, Barrat FJ, Banchereau J, Pascual V. Netting neutrophils are major inducers of type I IFN production in pediatric systemic lupus erythematosus. Sci Transl Med 2011; 3 (73): 73ra20.

[14] Gaspar D, Salomé Veiga A, Castanho MarB. From antimicrobial to anticancer peptides. A review. Front Microbiol. 2013; 4: 294.

[15] Gilliet M, Lande R. Antimicrobial peptides and self-DNA in autoimmune skin inflammation. Curr Opin Immunol 2008; 20 (4): 401-7.

[16] Girnita A, Zheng H, Grönberg A, Girnita L, StÄhle M. Identification of the cathelicidin peptide LL37 as agonist for the type I insulin-like growth factor receptor. Oncogene 2012; 31(3): 352-65.

[17] Gupta AK, Joshi MB, Philippova M, Erne P, Hasler P, Hahn S, Resink TJ. Activated endothelial cells induce neutrophil extracellular traps and are susceptible to NETosis-mediated cell death. FEBS Lett 2010; 584 (14): 3193-7.

[18] Hakkim A, Fürnrohr BG, Amann K, Laube B, Abed UA, Brinkmann V, Herrmann M, Voll RE, ZyCHLINSKY A. Impairment of neutrophil extracellular trap degradation is associated with lupus nephritis. Proc Natl Acad Sci USA 2010; 107 (21): 9813-8.

[19] Hoffmann MH, Bruns H, Bäckdahl L, Neregård P, Niederreiter B, Herrmann M, Catrina Ai, AgerBERTh B, HoLmDAHL R. The cathelicidins LL-37 and rCRAMP are associated with pathogenic events of arthritis in humans and rats. Ann Rheum Dis 2013; 72 (7): 1239-48.

[20] Hu H, WANG CH, Guo X, Li W, WANG Y, HE Q. Broad activity against porcine bacterial pathogens displayed by two insect antimicrobial peptides moricin and cecropin. B Mol Cells $; 2013 ; 35$ (2): 106-114.

[21] Inomata M, Into T, Murakami Y. Suppressive effect of the antimicrobial peptide LL-37 on expression of IL-6, IL-8 and CXCL10 induced by Porphyromonas gingivalis cells and extracts in human gingival fibroblasts. Eur J Oral Sci 2010; 118: 574-581. 
[22] Jo EK. Innate immunity to mycobacteria: vitamin D and autophagy. Cell Microbiol 2010; 12 (8): 1026-35.

[23] JönSSON D, NiLSSON BO. The antimicrobial peptide LL-37 is anti-inflammatory and proapoptotic in human periodontal ligament cells. J Periodontal Res 2012; 47 (3): 330-5.

[24] Kahlenberg JM, Carmona-Rivera C, Smith CK, Kaplan MJ. Neutrophil extracellular trap-associated protein activation of the NLRP3 inflammasome is enhanced in lupus macrophages. J Immunol 2013; 190 (3): 1217-26.

[25] Kreuter A, Jaouhar M, Skrygan M, Tigges C, Stücker M, Altmeyer P, Gläser R, Gambichler T. Expression of antimicrobial peptides in different subtypes of cutaneous lupus erythematosus. J Am Acad Dermatol 2011; 65 (1): 125-33.

[26] Lande R, Ganguly D, Facchinetti V, Frasca L, Conrad C, Gregorio J, Meller S, Chamilos G, Sebasigari R, Riccieri V, Bassett R, Amuro H, Fukuhara S, Ito T, Liu YJ, Gilliet M. Neutrophils activate plasmacytoid dendritic cells by releasing self-DNA-peptide complexes in systemic lupus erythematosus. Sci Transl Med 2011; 3 (73): 73ra19.

[27] Leshner M, Wang S, Lewis C, Zheng H, Chen XA, Santy L, Wang Y. PAD4 mediated histone hypercitrullination induces heterochromatin decondensation and chromatin unfolding to form neutrophil extracellular trap-like structures. Front Immunol 2012; 3: 307.

[28] Leung TF, Ching KW, Kong AP, Wong GW, Chan JC, Hon KL. Circulating LL-37 is a biomarker for eczema severity in children. J Eur Acad Dermatol- Venereol 2012; 26 (4): 518-22.

[29] Maccari G, Di luca M, Nifosí R, Cardarelli F, Signore G, Boccardi C, Bifone A. Antimicrobial peptides design by evolutionary multiobjective optimization. PLoS Comput Biol 2013; 9 (9).

[30] Mader S, Ewen C, Hancock Re, Bleackley RC. The human cathelicidin, Ll-37, induces granzyme-mediated apoptosis in regulatory T cells. J Immunother 2011; 34 (3): 229-35.

[31] MÉndeZ-SAMPERIO P. The human cathelicidin hCAP18/LL-37: a multifunctional peptide involved in mycobacterial infections. Peptides 2010; (9): 1791-8.

[32] Méndez-Samperio P. Recent advances in the field of antimicrobial peptides in inflammatory diseases. Adv Biomed Res. 2013; 2: 50.

[33] Metzler KD, Fuchs TA, Nauseef WM, Reumaux D, Roesler J, Schulze I, Wahn V, Papayannopoulos $\mathrm{V}$, ZyChLinsky A. Myeloperoxidase is required for neutrophil extracellular trap formation: implications for innate immunity. Blood 2011; 117 (3): 953-9.

[34] Mookherjee N, Lippert DN, Hamill P, Falsafi R, Nijnik A, Kindrachuk J, Pistolic J, Gardy J, Miri P, NAseer M, Foster LJ, Hancock RE. Intracellular receptor for human host defense peptide LL-37 in monocytes. J Immunol 2009; 183 (4): 2688-96.

[35] Neeli I, Khan SN, Radic M. Histone deimination as a response to inflammatory stimuli in neutrophils. J Immunol 2008; 180 (3): 1895-902.

[36] Nishinaka Y, Arai T, Adachi S, Takaori-Kondo A, Yamashita K. Singlet oxygen is essential for neutrophil extracellular trap formation. Biochem Biophys Res Commun 2011; 413 (1): 75-9.

[37] Niyonsaba F, Ushio H, Hara M, Yokoi H, Tominaga M, Takamori K, Kajiwara N, Saito H, NagaoKa I, Ogawa H, Oкumura K. Antimicrobial peptides human beta-defensins and cathelicidin LL-37 induce the secretion of a pruritogenic cytokine IL-31 by human mast cells. J Immunol 2010; 184 (7): 3526-34.

[38] Overhage J, Campisano A, Bains M, Torfs EC, Rehm BH, Hancock RE. Human host defense peptide LL-37 prevents bacterial biofilm formation. Infect Immun 2008; 76 (9): 4176-82.

[39] Park HJ, Cho DH, Kim HJ, Lee JY, Cho BK, Bang SI, Song SY, Yamasaki K, Di Nardo A, Gallo RL. Collagen synthesis is suppressed in dermal fibroblasts by the human antimicrobial peptide LL-37. J Invest Dermatol 2009; 129 (4): 843-50.

[40] Pazgier M, Ericksen B, Ling M, Toth E, Shi J, Li X, Galliher-Beckley A, Lan L, Zou G, Zhan G, Yuan W, Pozharski E, Lu W. Structural and functional analysis of the pro-domain of human cathelicidin, LL-37. Biochemistry 2013; 52 (9): 1547-1558. 
[41] Ren SX, Cheng AS, To KF, Tong JH, Li MS, Shen J, Wong CC, Zhang L, Chan RL, Wang XJ, Ng SS, Chiu lC, Marquez Ve, Gallo RL, Chan FK, Yu J, Sung JJ, Wu WK, Cho CH. Host immune defense peptide LL-37 activates caspase-independent apoptosis and suppresses colon cancer. Cancer Res 2012; 72 (24): 6512-23.

[42] Sсніттек B. The antimicrobial skin barrier in patients with atopic dermatitis. Curr Probl Dermatol 2011; 41: 54-67.

[43] Soehnlein O, Zernecke A, Eriksson Ee, Rothfuchs AG, Pham CT, Herwald H, Bidzhekov K, RotTenberg ME, Weber C, Lindbom L. Neutrophil secretion products pave the way for inflammatory monocytes. Blood 2008; 112 (4): 1461-71.

[44] SHIN DM, JO EK. Antimicrobial peptides in innate immunity against Mycobacteria. Immune Netw 2011; 11(5): 245-52.

[45] Sun CL, Zhang FZ, Li P, Bi LQ. LL-37 expression in the skin in systemic lupus erythematosus. Lupus 2011; 20 (9): 904-11.

[46] Suphasiriroj W, Mikami M, Shimomura H, Sato S. Specificity of antimicrobial peptide LL-37 to neutralize periodontopathogenic lipopolysaccharide activity in human oral fibroblasts. J Periodontol 2013; 84 (2): 256-64.

[47] Termén S, Tollin M, Rodriguez E, Sveinsdóttir SH, Jóhannesson B, Cederlund A, SJövall J, AgerBerth B, Gudmundsson GH. PU.1 and bacterial metabolites regulate the human gene CAMP encoding antimicrobial peptide LL-37 in colon epithelial cells. Mol Immunol 2008; 45 (15): 3 947-55.

[48] Tomasinsig L, Pizzirani C, Skerlavaj B, Pellegatti P, Gulinelli S, Tossi A, di Virgilio F, Zanetti M. The human cathelicidin LL-37 modulates the activities of the $\mathrm{P} 2 \mathrm{X}_{7}$ receptor in a structure-dependent manner. J Biol Chem 2008; 283 (45): 30471-30481.

[49] Wang Y, Li M, Stadler S, Correll S, Li P, Wang D, Hayama R, Leonelli L, Han H, Grigoryev Sa, Allis CD, Coonrod SA. Histone hypercitrullination mediates chromatin decondensation and neutrophil extracellular trap formation. J Cell Biol 2009; 184 (2): 205-13.

[50] WitKowska D, Bartyś A, Gamian A. Defensins and cathelicidins as natural peptide antibiotics. Postepy Hig Med Dosw, 2008; 62: 694-707.

[51] Vandamme D, Landuyt B, Luyten W, Schoofs L. A comprehensive summary of LL-37, the factoctum human cathelicidin peptide. Cell Immunol 2012; 280 (1): 22-35.

[52] Villanueva E, Yalavarthi S, Berthier CC, Hodgin JB, Khandpur R, Lin AM, Rubin CJ, Zhao W, Olden SH, Klinker M, Shealy D, Denny MF, Plumas J, Chaperot L, Kretzler M, Bruce AT, Kaplan MJ. Netting neutrophils induce endothelial damage, infiltrate tissues, and expose immunostimulatory molecules in systemic lupus erythematosus. J Immunol 2011; 187 (1): 538-52.

[53] Yu Y, Su K. Neutrophil Extracellular Traps and Systemic Lupus Erythematosus J Clin Cell Immunol 2013; 4: 139.

[54] Zawrotniak M, Rapala-KoziK M. Neutrophil extracellular traps (NETs) - formation and implications. Acta Pol Bioch 2013; 60 (3): 277-284.

[55] Zhang Z, Cherryholmes G, Shively JE. Neutrophil secondary necrosis is induced by LL-37 derived from cathelicidin. J Leukoc Biol 2008; 84 (3): 780-8.

Editor-Michat Nowicki

Professor Zofia Niemir, M.D. Ph.D

Laboratory for Molecular Nephrology

Department of Nephrology, Transplantology and Internal Medicine

Poznań University od Medical Sciences,

Przybyszewskiego 49 Street, 60-355 Poznań, Poland

phone: 48-61-8691768, 48-692358165

e-mail: zniemir@ump.edu.pl 